\title{
Phase II study of irinotecan (CPT-11) in children with high-risk malignant brain tumors: The Duke experience ${ }^{1}$
}

\author{
Christopher D. Turner, Sridharan Gururangan, ${ }^{2}$ James Eastwood, Krystal Bottom, \\ Melody Watral, Rodney Beason, Roger E. McLendon, Allan H. Friedman, Sandra \\ Tourt-Uhlig, Langdon L. Miller, and Henry S. Friedman \\ The Brain Tumor Center at Duke (C.D.T, S.G., K.B., M.W., S.T.-U., H.S.F.) and the Divisions of Neuro- \\ Radiology (J.E.), Pathology (R.E.M.), and Neurosurgery (A.H.F.), Duke University Medical Center, Durham, NC \\ 27710; and Pharmacia and Upjohn (R.B., L.L.M.), Kalamazoo, MI 49001
}

A phase II study of irinotecan (CPT-11) was conducted at Duke University Medical Center, Durham, NC, to evaluate the activity of this agent in children with high-risk malignant brain tumors. A total of 22 children were enrolled in this study, including 13 with histologically verified recurrent malignant brain tumors (glioblastoma multiforme $[\mathrm{GBM}] 4$, anaplastic astrocytoma 1 , ependymoma 5 , and medulloblastoma/primitive neuroectodermal tumor 3), 5 with recurrent diffuse pontine glioma, and 4 with newly diagnosed GBM. All patients with recurrent tumor had prior chemotherapy and/or irradiation. Each course of CPT-11 consisted of $125 \mathrm{mg} / \mathrm{m}^{2}$ per week given i.v. for 4 weeks followed by a 2 -week rest period. Patients with recurrent tumors received therapy until disease progression or unacceptable toxicity. Patients with newly diagnosed tumors initially received 3 cycles of treatment to assess tumor response and then were allowed radiotherapy at physician's choice; patients who demonstrated a response to CPT-11 prior to radiotherapy were allowed to continue the drug after radiation until disease progression or unacceptable toxicity. A $25 \%$ to $50 \%$ dose reduction was made for grade III-IV toxicity. Responses were assessed after every course by gadolinium-enhanced MRI

Received 30 July 2001, accepted 26 November 2001.

${ }^{1}$ The study was presented in part at the 9th International Symposium of Pediatric Neuro-Oncology held in San Francisco, California, in June 2000.

${ }^{2}$ Address correspondence and reprint requests to Sridharan Gururangan, The Brain Tumor Center at Duke, Duke University Medical Center, Box 3624, Durham, NC 27710.

${ }^{3}$ Abbreviations used are as follows: $\mathrm{CR}$, complete response; GBM, glioblastoma multiforme; $\mathrm{PR}$, partial response. of the brain and spine. Twenty-two patients received a median of 2 courses of CPT-11 (range, 1-16). Responses were seen in 4 of 9 patients with GBM or anaplastic astrocytoma (44\%; $95 \%$ confidence interval, $11 \%-82 \%$ ) (complete response in 2 patients with recurrent GBM lasting 9 months and 48+ months; partial response in one patient with a newly diagnosed midbrain GBM lasting 18 months prior to radiotherapy; and partial response lasting 11 months in 1 patient with recurrent anaplastic astrocytoma), 1 of 5 patients with recurrent ependymoma (partial response initially followed by stable disease lasting 11 months), and none of 5 patients with recurrent diffuse pontine glioma. Two of 3 patients with medulloblastoma/ primitive neuroectodermal tumor had stable disease for 9 and 13 months. Toxicity was mainly myelosuppression, with 12 of 22 patients $(50 \%)$ suffering grade II-IV neutropenia. Seven patients required dose reduction secondary to neutropenia. CPT-11, given in this schedule, appears to be active in children with malignant glioma, medulloblastoma, and ependymoma with acceptable toxicity. Ongoing studies will demonstrate if activity of CPT11 can be enhanced when combined with alkylating agents, including carmustine and temozolomide. NeuroOncology 4, 102-108, 2002 (Posted to Neuro-Oncology [serial online], Doc. 01-043, February 11, 2002. URL $<$ neuro-oncology.mc.duke.edu>)

$\mathrm{T}$ Therapy for children with malignant brain tumors is frequently unsuccessful. Although as many as $50 \%$ of patients will respond to first-line therapy consisting of surgery, radiation therapy, and chemotherapy, a significant proportion will ultimately experience recurrent disease. Currently, salvage therapy for recurrent CNS tumors is not well defined. Although high-dose chemotherapy regimens are useful in producing pro- 
longed disease-free remissions in a subset of patients with recurrent medulloblastoma and malignant glioma (Dunkel et al., 1998; Finlay, 1999; Finlay et al., 1996; Graham et al., 1997), most children with these tumors will eventually die of disease. Treatment failure reflects the current limitations in the activity of available chemotherapy, the emergence of resistance to these agents, and the difficulty in delivering these drugs to at least partially privileged intracranial sites (Feun et al., 1994; Henson et al., 1992; Phillips, 1991). New agents with novel mechanisms of action are required to improve survival of these patients.

Irinotecan (CPT-11, Camptosar; Pharmacia and Upjohn, Kalamazoo, Mich.), a camptothecin analog and a topoisomerase I inhibitor, was synthesized to impart increased aqueous solubility, greater efficacy, and less toxicity than the parent camptothecin (Slichenmyer et al., 1994). It is metabolized mainly in the liver by carboxylesterase enzymes to form SN-38, a compound that is 1000 times more potent as an inhibitor of topoisomerase I (Kawato et al., 1991; Kono and Hara, 1991; Pommier et al., 1994). CPT-11 has been shown in preclinical studies to produce statistically significant tumor regressions in mouse xenografts derived from ependymomas, high-grade gliomas, and medulloblastomas (Hare et al., 1997; Vassal et al., 1997, 1998).

We previously reported favorable activity of CPT-11 in adults with recurrent or progressive malignant gliomas (Friedman et al., 1999). We now report on the activity and toxicity of this agent in children with high-risk malignant brain tumors.

\section{Patients And Methods}

\section{Eligibility Criteria}

Eligibility criteria for this study included children between the ages of 3 to 21 years; newly diagnosed $\mathrm{GBM}^{3}$ or any recurrent malignant brain tumor with histologic verification of disease, except for patients with diffuse pontine glioma who did not require biopsy confirmation before enrollment; radiologic evidence of measurable disease on a contrast-enhanced MRI scan of brain or spine obtained within 2 weeks of study entry; time interval of at least 3 weeks after previous irradiation or chemotherapy; stable or decreasing dose of corticosteroids for at least 1 week prior to study entry; evidence of adequate organ function as indicated by a hematocrit of $>29 \%$, absolute neutrophil $>1500$ cells $/ \mu$ l, platelet count $>125,000$ cells $/ \mu l$, serum creatinine level $<1.5 \mathrm{mg} / \mathrm{dl}$, blood urea nitrogen level, $25 \mathrm{mg} / \mathrm{dl}$, and serum aspartate aminotransferase and total bilirubin $<1.5$ times upper limit of institutional normal; Lansky or Karnofsky score of $>60 \%$; adequate birth control measures for the duration of treatment in girls of childbearing age; and signed informed consent as approved by the Institutional Review Board obtained before entry on the study.

Patients were excluded if they had received more than 1 prior chemotherapy regimen, were on comedications (immunosuppressive agents, other experimental or chemotherapy drugs) that might interfere with the study results except anticonvulsants and/or corticosteroids, or were pregnant or breast feeding.

\section{Drug Administration and Dose Modifications}

CPT-11 was supplied by the Cancer Therapy Evaluation Program of the National Cancer Institute as a $20 \mathrm{mg} / \mathrm{ml}$ sterile solution. It was mixed with $5 \%$ dextrose to yield a concentration of $1 \mathrm{mg} / \mathrm{ml}$ and administered at a constant rate over $90 \mathrm{~min}$ through a free-flowing i.v. catheter. A starting dose of $125 \mathrm{mg} / \mathrm{m}^{2}$ was used. A treatment cycle consisted of 4 weekly administrations of CPT-11 followed by a rest period of 2 weeks.

Toxicity during treatment was graded according to the National Cancer Institute Common Toxicity Criteria, Version 2.0. Dose modification was based on the maximum preceding toxicity experienced by each patient. The dose of CPT-11 during a course or for subsequent courses was modified according to a scheme as previously reported (Friedman et al., 1999) and is indicated in Table 1. Patients with recurrent tumors received CPT-11 until progressive disease or unacceptable toxicity. Patients with newly diagnosed tumors were treated for 18 weeks (three 6-week cycles) before receiving external beam radiotherapy, unless progressive tumor occurred during treatment. Patients who demonstrated a response were eligible for further treatment with CPT-11 after radiotherapy and until tumor progression or unacceptable toxicity.

\section{Supportive Care}

Anti-emetic prophylaxis consisted of a single dose of ondansetron $\left(0.45 \mathrm{mg} / \mathrm{m}^{2}\right)$ and dexamethasone $\left(4-8 \mathrm{mg} / \mathrm{m}^{2}\right)$ before each dose of CPT-11. Anticonvulsants, if any, were continued through the study. Atropine was administered for cramping and/or diarrhea within $1 \mathrm{~h}$ after infusion. For late onset diarrhea, patients were instructed to take loperamide $(0.4-0.8 \mathrm{mg} / \mathrm{kg}$ per $24 \mathrm{~h})$ every $6 \mathrm{~h}$ until diarrhea resolved.

\section{Evaluation During Therapy}

Complete physical and neurologic exams were performed before each course of therapy. Laboratory evaluation during the study consisted of a complete blood cell count with differential twice a week. Serum chemistries were obtained every 6 weeks. Anticonvulsant levels were monitored as clinically indicated.

Responses were assessed based on a gadoliniumenhanced MRI of the brain and or spine before each course of therapy using the product of the maximum bidimensional tumor diameters. Responses were defined as follows: complete response, disappearance of all enhancing tumor on consecutive contrast-enhanced MRI scans 6 weeks apart, off steroids and neurologically stable or improved; partial response, at least $50 \%$ reduction in the size of the enhancing tumor maintained for at least 6 weeks, steroid dose stable or reduced and neurologically stable or improved; progressive disease, increase in size of enhancing tumor by at least $25 \%$ or appearance of any new tumor, or neurologically worse and steroid dose stable or increased; stable disease, any changes in tumor size that did not qualify for complete response, partial response, or progressive disease classification. 
Table 1. Recommended dose modifications

At start of subsequent Toxicity $\mathrm{NCl}$ grade $^{\mathrm{a}}$ (value)

\begin{tabular}{lll}
\hline Myelotoxicity & Maintain dose level & Maintain dose level \\
II & Decrease by $25 \mathrm{mg} / \mathrm{m}^{2}$ & Maintain dose level \\
III & Omit dose, then decrease by $25 \mathrm{mg} / \mathrm{m}^{2}$ when resolved to $<$ grade II & Decrease by $25 \mathrm{mg} / \mathrm{m}^{2}$ \\
IV & Omit dose, then decrease by $50 \mathrm{mg} / \mathrm{m}^{2}$ when resolved to $<$ grade II & Decrease by $50 \mathrm{mg} / \mathrm{m}^{2}$ \\
GI (diarrhea) & & Maintain dose level \\
I & Maintain dose level & Maintain dose level \\
II & Decrease by $25 \mathrm{mg} / \mathrm{m}^{2}$ & Decrease by $25 \mathrm{mg} / \mathrm{m}^{2}$ \\
III & Omit dose, then decrease by $25 \mathrm{mg} / \mathrm{m}^{2}$ when resolved to $<$ grade II & Decrease by $50 \mathrm{mg} / \mathrm{m}^{2}$ \\
IV & Omit dose, then decrease by $50 \mathrm{mg} / \mathrm{m}^{2}$ when resolved to $<$ grade II & \\
Other nonhematologic & & \\
toxicities & & \\
I & Maintain dose level & Maintain dose level \\
II & Decrease by $25 \mathrm{mg} / \mathrm{m}^{2}$ & Decrease by $25 \mathrm{mg} / \mathrm{m}^{2}$ \\
III & Omit dose, then decrease by $25 \mathrm{mg} / \mathrm{m}^{2}$ when resolved to $<$ grade II & Decrease by $50 \mathrm{mg} / \mathrm{m}^{2}$ \\
IV & Omit dose, then decrease by $50 \mathrm{mg} / \mathrm{m}^{2}$ when resolved to $<$ grade II & Decrease by $50 \mathrm{mg} / \mathrm{m}^{2}$ \\
\hline
\end{tabular}

Abbreviations: Gl, gastrointestinal.

a National Cancer Institute Common Toxicity Criteria.

\section{Statistical Considerations}

The initial plan was to divide the enrollment of pediatric patients into 4 histologic strata (malignant glioma, diffuse pontine glioma, ependymoma, and primitive neuroectodermal tumor) with stopping rules for each stratum according to a conventional phase II study; however, the drug sponsor (Pharmacia and Upjohn) limited the pediatric study to a total of 22 patients. Because of the small number of patients in each histologic group, the statistical significance of the responses obtained in each group (except patients with malignant glioma) could not be ascertained with confidence.

\section{Results}

Between April 1997 and March 1999, a total of 22 children were enrolled on this study. The median age at the time of enrollment was 10 years (range, 3-19 years) (Table 2). Four patients with GBM had received no prior therapy. The remaining 18 patients with recurrent malignant brain tumors had prior therapy including surgery and/or radiotherapy. Twelve of these patients had also received prior chemotherapeutic agents including vincristine, nitrosoureas, procarbazine, cisplatin, etoposide, cyclophosphamide, or topotecan (Table 2). During the study, 3 patients were on anticonvulsant therapy with dilantin.

\section{Efficacy}

Tumor responses were seen in 4 of 9 patients with GBM or anaplastic astrocytoma (CR 2, PR 2), with an objective response rate of $44 \%$ (95\% confidence interval, $11 \%$ $82 \%$ ). One patient (no. 2, Table 3 and Fig. 1) with a recurrent cerebral GBM who achieved a CR following CPT-11 treatment is now alive and disease free 3 years after stopping therapy. Another patient (no. 3, Table 3 and Fig. 2), with a newly diagnosed GBM of the midbrain, achieved a PR after treatment, a response that was maintained through
18 months of therapy with CPT-11 (radiotherapy was deferred due to parental choice). She subsequently received focal irradiation and is currently alive with no evidence of disease recurrence more than 2 years since starting therapy. The third patient (no. 1, Table 3), who had a recurrent GBM and achieved a CR after 9 courses of CPT-11, subsequently died of disease progression. One patient with a recurrent cerebral anaplastic astrocytoma (no. 4, Table 3) had a PR after 12 cycles of CPT-11 that was maintained for another 6 months after cessation of therapy. Two additional patients, 1 with newly diagnosed GBM (no. 5, Table 3 ) and 1 with recurrent GBM (no. 6, Table 3), had stable disease for more than 12 weeks from starting therapy. One patient with ependymoma (no. 11, Table 3) had a PR to CPT-11 that was maintained for 12 months. Stable disease was observed in 1 patient with ependymoma and 2 patients with primitive neuroectodermal tumor. All 5 patients with diffuse pontine glioma suffered progressive disease after treatment.

\section{Toxicity}

Toxicity was mainly neutropenia and diarrhea (Table 3). Neutropenia was grade IV in 1 patient, grade III in 4 patients, grade II in 7 patients, and grade I in 3 patients (Table 3 ). Seven of these patients required dose reductions secondary to neutropenia. Five patients experienced either grade I $(n=3)$ or grade II $(n=2)$ diarrhea. Seven patients who received no more than 2 cycles of treatment did not experience any toxicity from this agent. No patient required red cell or platelet transfusions. There were no deaths related to toxicity.

\section{Discussion}

The dismal outcome with standard therapy in children with high-risk malignant brain tumors has led to the exploration and use of new chemotherapeutic agents with novel mechanisms of action and potentially enhanced activity in these tumors. 
Table 2. Clinical characteristics, tumor histology, and prior treatment of 22 patients with malignant brain tumors treated with CPT-11

\begin{tabular}{|c|c|c|c|c|c|}
\hline Patient no. & Age (yrs)/sex & Diagnosis & New/recurrent & Prior treatment & Time to relapse ${ }^{a}$ (months) \\
\hline 1 & $4 / M$ & GBM & Recurrent & $\mathrm{XRT}, \mathrm{VCR}, \mathrm{CCNU}, \mathrm{PCB}$ & 2 \\
\hline 2 & $19 / F$ & GBM & Recurrent & $\mathrm{XRT}, \mathrm{BCNU}, \mathrm{CDDP}$ & 36 \\
\hline 3 & $6 / F$ & GBM & New & None & NA \\
\hline 4 & $7 / F$ & AA & Recurrent & XRT, VCR, CDDP, VP, CPM & 5 \\
\hline 5 & $6 / M$ & GBM & New & None & NA \\
\hline 6 & $17 / M$ & GBM & Recurrent & XRT, CPM, VCR & 2 \\
\hline 7 & $16 / M$ & GBM & New & None & NA \\
\hline 8 & $11 / M$ & GBM & Recurrent & XRT, VCR, CDDP, VP, CPM & 1.5 \\
\hline 9 & $8 / M$ & GBM & New & None & NA \\
\hline 10 & $8 / M$ & EPN & Recurrent & XRT & 2 \\
\hline 11 & $11 / \mathrm{F}$ & EPN & Recurrent & XRT & 24 \\
\hline 12 & $3 / M$ & EPN & Recurrent & $\mathrm{XRT}, \mathrm{VCR}, \mathrm{CDDP}, \mathrm{CPM}$ & 24 \\
\hline 13 & $11 / F$ & EPN & Recurrent & XRT & 24 \\
\hline 14 & $11 / M$ & EPN & Recurrent & XRT & 72 \\
\hline 15 & $7 / M$ & DPG & Recurrent & XRT, topotecan & 6 \\
\hline 16 & $13 / F$ & DPG & Recurrent & XRT & 2 \\
\hline 17 & $6 / F$ & DPG & Recurrent & XRT & 22 \\
\hline 18 & $6 / M$ & DPG & Recurrent & $X R T, V P$ & 9 \\
\hline 19 & $11 / \mathrm{F}$ & DPG & Recurrent & $\mathrm{XRT}, \mathrm{VP}$ & 4 \\
\hline 20 & $17 / F$ & PNET & Recurrent & $X R T, V C R, C D D P, V P, C P M$ & 72 \\
\hline 21 & $11 / M$ & PNET & Recurrent & XRT, VCR, CDDP, VP, CPM & 48 \\
\hline 22 & $9 / M$ & PNET & Recurrent & $\mathrm{XRT}, \mathrm{CPM}$ & 12 \\
\hline
\end{tabular}

Abbreviations: GBM, glioblastoma multiforme; XRT, radiotherapy; VCR, vincristine; CCNU, lomustine; PCB, procarbazine; BCNU, carmustine; CDDP, cisplatin; VP, VP-16; $A A$, anaplastic astrocytoma; CPM, cyclophosphomide; EPN, ependymoma; DPG, diffuse pontine glioma; NA, not applicable; PNET, primitive neuroectodermal tumor.

anterval from previous radiotherapy to relapse.

In preclinical studies, CPT-11, a topoisomerase I inhibitor, has been shown by our group and others to have marked activity against a broad panel of CNS xenografts implanted in athymic nude mice (Hare et al., 1997; Vassal et al., 1997, 1998). Using a protracted schedule of daily administration at 5 days a week for 2 weeks, Hare et al. (1997) reported significant growth delays in all s.c. xenografts of childhood malignant glioma, ependymoma, and medulloblastoma including xenografts derived from tumor sublines resistant to alkylating agents. Vassal et al. (1997), using a similar schedule, reported favorable response and prolongation of survival in nude mice bearing medulloblastoma xenografts. Early pivotal trials of CPT-11 in the United States have established dose and schedule dependency of CPT-11 in various adult solid tumors. Rothenberg et al. (1998) conducted a phase I study of CPT-11 in 32 adult patients with recurrent solid tumors who had prior chemotherapy and/or radiation. The drug was given as a single 90-min infusion every week for 4 weeks with a 2 -week rest period. Dose-limiting toxicities were mainly diarrhea and neutropenia. The maximum tolerated dose of CPT-11 in this study was $150 \mathrm{mg} / \mathrm{m}^{2}$ per week. On the basis of the favorable tumor responses to CPT-11 in the preclinical studies and using the maximum tolerated dosage previously determined in the weekly schedule of CPT-11 (Rothenberg et al., 1998; von Hoff, 1996), we performed a phase II study to assess the activity and toxicity of CPT-11 in adults with recurrent malignant gliomas and children with high-risk malignant brain tumors using a starting dose of $125 \mathrm{mg} / \mathrm{m}^{2}$ per week for 4 weeks. In a recent publication, Friedman et al. (1999), reporting on the adult patients in this study, showed a $15 \%(95 \%$ confidence interval, 6\%-24\%) objective response in 60 patients with recurrent or progressive malignant glioma, with a median overall survival of 43 weeks. Also, a favorable response to CPT- 11 predicted a longer duration of survival in these patients. Consistent with the favorable preclinical responses with CPT-11 observed in malignant glioma xenografts in our laboratory, we are reporting a response rate of more than $40 \%$ in children with malignant glioma, with 1 patient alive and disease free more than 2 years after cessation of CPT-11 therapy and another alive and well after 1 year of CPT-11 and subsequent focal radiotherapy. However, this data should be interpreted cautiously because of the small number of patients treated in this study. In contrast, few objective responses were observed in patients with other tumor histologies even when significant responses were observed with such tumors in the preclinical setting. This could be partly explained by the greater tolerance of mice for high systemic exposures of SN-38 (Houghton et al., 1998), the different and less protracted dose schedule in the patients studied as compared to mice, or inherent drug resistance in these tumors (Chen et al., 1999a, 1999b; Chu et al., 1999).

Other studies of CPT-11 in pediatric brain tumors reported on its activity in the context of phase I studies (Blaney et al., 2001; Furman et al., 1999). Furman et al. 
Table 3. Response, toxicity, and outcome of 22 patients with malignant brain tumors treated with CPT-11

\begin{tabular}{|c|c|c|c|c|c|c|}
\hline $\begin{array}{l}\text { Patient } \\
\text { no. }\end{array}$ & $\begin{array}{l}\text { No. of cycles } \\
\text { CPT-11 }\end{array}$ & Anti-convulsants & Best response & $\begin{array}{l}\text { Lowest dose } \\
\text { CPT-11 }\left(\mathrm{mg} / \mathrm{m}^{2}\right)\end{array}$ & Worst toxicity & Outcome \\
\hline 1 & 7 & Dilantin & $\mathrm{CR} \times 9 \mathrm{mos}$ & 100 & Grade II neutropenia & Dead \\
\hline 2 & 10 & None & $C R \times 48+\operatorname{mos}$ & 25 & Grade II neutropenia & Alive, NED \\
\hline 3 & 16 & None & $\mathrm{PR} \times 18$ mos then $\mathrm{XRT}$ & 100 & $\begin{array}{l}\text { Grade II neutropenia, } \\
\text { grade II diarrhea }\end{array}$ & Alive, NED \\
\hline 4 & 12 & Dilantin & $\mathrm{PR} \times 18 \mathrm{mos}$ & 100 & Grade II neutropenia & Dead \\
\hline 5 & 4 & None & SD $\times 6$ mos then $\mathrm{XRT}$ & 100 & $\begin{array}{l}\text { Grade III neutropenia, } \\
\text { grade II diarrhea }\end{array}$ & Alive, NED \\
\hline 6 & 4 & None & $\mathrm{SD} \times 4 \mathrm{mos} / \mathrm{PD}$ & 125 & Grade II neutropenia & Dead \\
\hline 7 & 1 & None & PD & 125 & None & Dead \\
\hline 8 & 1 & Dilantin & PD & 125 & None & Dead \\
\hline 9 & 1 & None & PD & 125 & None & Dead \\
\hline 10 & 9 & None & PR then SD $\times 11$ mos & 50 & Grade IV neutropenia & Dead \\
\hline 11 & 2 & None & PD & 100 & Grade III neutropenia & Dead \\
\hline 12 & 2 & None & PD & 125 & $\begin{array}{l}\text { Grade I neutropenia, } \\
\text { grade I diarrhea }\end{array}$ & $\begin{array}{c}\text { Alive, with } \\
\text { disease }\end{array}$ \\
\hline 13 & 2 & None & PD & 125 & Grade II neutropenia & Dead \\
\hline 14 & 4 & None & $\mathrm{SD} \times 4 \mathrm{mos}$ & 125 & Grade III neutropenia & $\begin{array}{c}\text { Alive, with } \\
\text { disease }\end{array}$ \\
\hline 15 & 2 & None & PD & 125 & None & Dead \\
\hline 16 & 1 & None & PD & 125 & Grade I neutropenia & Dead \\
\hline 17 & 2 & None & PD & 125 & None & Dead \\
\hline 18 & 1 & None & PD & 125 & None & Dead \\
\hline 19 & 1 & None & PD & 125 & None & Dead \\
\hline 20 & 13 & None & $\mathrm{SD} \times 19 \mathrm{mos}$ & 125 & Grade III neutropenia & Dead \\
\hline 21 & 6 & None & $\mathrm{SD} \times 19 \mathrm{mos}$ & 125 & $\begin{array}{l}\text { Grade II neutropenia, } \\
\text { grade I diarrhea }\end{array}$ & Dead \\
\hline 22 & 1 & None & PD & 125 & Grade I diarrhea & Dead \\
\hline
\end{tabular}

Abbreviations: $C R$, complete response; NED, no evidence of disease; PR, partial response; XRT, radiotherapy; SD, stable disease; PD, progressive disease.
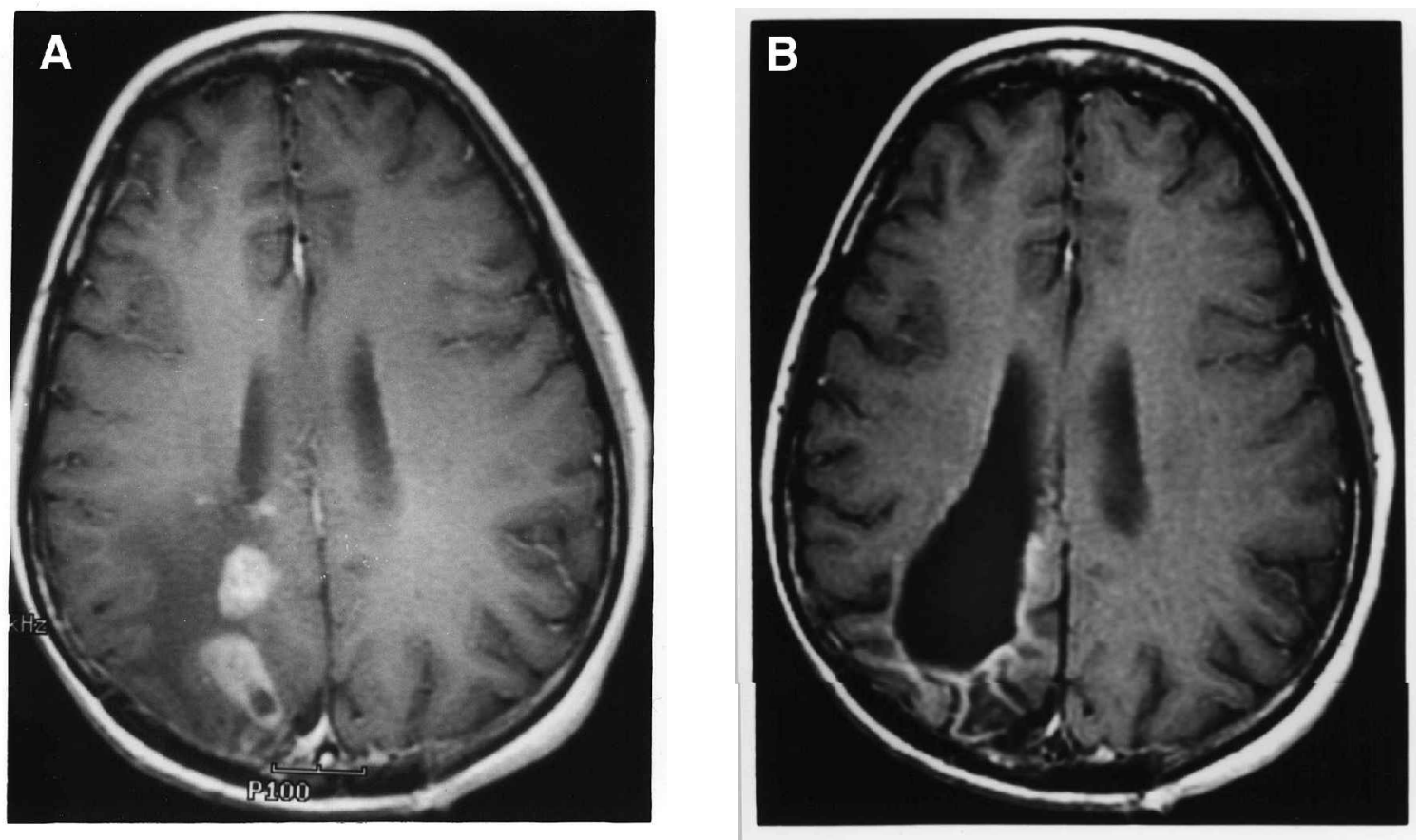

Fig. 1. Contrast-enhanced MRI scan of the brain of a 19-year-old female with GBM of the cerebral hemisphere (Patient no. 2) before (A) and after (B) 10 courses of CPT-11. 

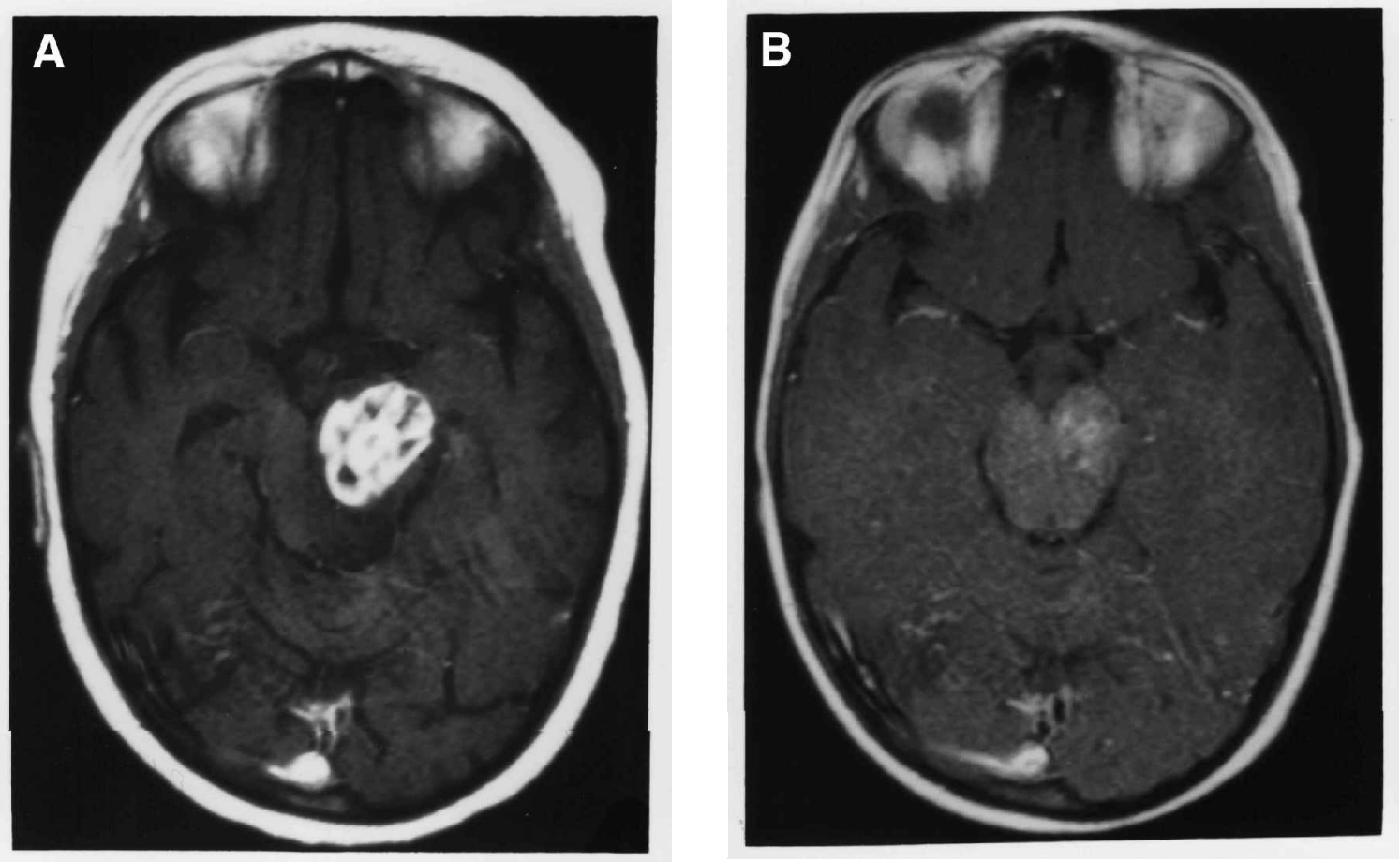

Fig. 2. Contrast-enhanced MRI scan of the brain of a 6-year-old female with GBM of the midbrain (Patient no. 3) before (A) and after (B) 5 courses of CPT-11.

(1999), using a protracted schedule of CPT-11 of daily administration for 5 days per week for 2 weeks every 21 days, treated 4 patients with brain tumors and did not note any response. In contrast, Blaney et al. (2001), using a similar prolonged but shorter schedule of daily administration for 5 days every 3 weeks, demonstrated stable disease in 4 patients with recurrent malignant brain tumors.

As expected from previous clinical studies of CPT-11, toxicity in our patients was limited to neutropenia and mild diarrhea. Grade II-IV neutropenia requiring dose reduction of CPT- 11 occurred in more than $50 \%$ of children compared with $10 \%$ of adult patients in the same study (Friedman et al., 1999). Most of the adult patients were on dexamethasone, phenobarbital, or dilantin, which are known inducers of the hepatic cytochrome P450 enzymes including CYP3A4 (Benedetti, 2000; Levy, 1995), leading to increased CYP3A4 activity and enhanced clearance of CPT-11 and its metabolites (Friedman et al., 1999; Santos et al., 2000; Ratain, 2000). However, most of the children in our study were not on any anticonvulsants, which might explain the higher incidence of bone marrow toxicity in these patients. We did not see any relationship between intensity of prior therapy and degree of neutropenia after CPT-11 treatment, with grade II-IV toxicity equally distributed in patients with or without prior intensive treatment. However, other pediatric studies of CPT-11 that used a prolonged schedule reported that myelotoxicity was dose limiting in heavily pretreated patients (Blaney et al., 2001; Furman et al., 1999).
Diarrhea was typically mild in children treated in our study, although most of them were not on anticonvulsants. Intestinal toxicity has been found to be dose limiting in phase I studies of CPT-11 when the drug is given in a prolonged schedule and is not related to the area under the concentration curve (Blaney et al., 2001; Furman et al., 1999). The incidence of diarrhea with CPT-11 also appears to be schedule dependent and more common with prolonged administration of the drug (Blaney et al., 2001; Ratain, 2000).

Although the favorable outcome in some patients with malignant glioma in our study is gratifying, small sample sizes in other histologic groups preclude assessment of true response rates in these tumors. Results from ongoing cooperative group phase II studies of this agent in children with recurrent solid tumors might soon be available and provide additional information regarding effectiveness of CPT-11 in other malignant brain tumors. Alternatively, it is possible that the activity of CPT-11 could be enhanced by sequential administration after an alkylator. Pourquier et al. (2001) have recently shown that there is an 8- to 10-fold enhancement of topoisomerase I cleavable complexes when alkylation occurs at position 6 of guanidine residues near topoisomerase I cleavage sites in DNA. Our group and others have recently shown that treatment of brain tumor xenografts with alkylating agents including carmustine and temozolomide followed by CPT-11 is synergistic (Coggins et al., 1998; Houghton et al., 2000; Patel et al., 2000). Phase I/II studies of these combinations in children and adults with recurrent malignant brain tumors are in progress at our institution. 


\section{References}

Benedetti, M.S. (2000) Enzyme induction and inhibition by new antiepileptic drugs: A review of human studies. Fundam. Clin. Pharmacol. 14, 301-319.

Blaney, S., Berg, S.L., Pratt, C., Weitman, S., Sullivan, J., LuchtmanJones, L., and Bernstein, M. (2001) A phase I study of irinotecan in pediatric patients: A Pediatric Oncology Group study. Clin. Cancer Res. 7, 32-37.

Chen, Z.S., Furukawa, T., Sumizawa, T., Ono, K., Ueda, K., Seto, K., and Akiyama, S.I. (1999a) ATP-dependent efflux of CPT-11 and SN-38 by the multidrug resistance protein (MRP) and its inhibition by PAK-104P. Mol. Pharmacol. 55, 921-928.

Chen, Z.S., Sumizawa, T., Furukawa, T., Ono, K., Tani, A., Komatsu, M., and Akiyama, S. (1999b) An enhanced active efflux of CPT-11 and SN-38 in cisplatin-resistant human KB carcinoma cells. Cancer Lett. 138, 13-22.

Chu, X.Y., Suzuki, H., Ueda, K., Kato, Y., Akiyama, S., and Sugiyama, Y. (1999) Active efflux of CPT-11 and its metabolites in human KB-derived cell lines. J. Pharmacol. Exp. Ther. 288, 735-741.

Coggins, C.A., Elion, G.B., Houghton, P.J., Hare, C.B., Keir, S., Colvin, O.M., Bigner, D.D., and Friedman, H.S. (1998) Enhancement of irinotecan (CPT11) activity against central nervous system tumor xenografts by alkylating agents. Cancer Chemother. Pharmacol. 41, 485-490.

Dunkel, I.J., Boyett, J.M., Yates, A., Rosenblum, M., Garvin, J.H., Bostrom, B.C., Goldman, S., Sender, L.S., Gardner, S.L., Li, H., Allen, J.C., and Finlay, J.L. (1998) High-dose carboplatin, thiotepa, and etoposide with autologous stem-cell rescue for patients with recurrent medulloblastoma. Children's Cancer Group. J. Clin. Oncol. 16, 222-228.

Feun, L.G., Savaraj, N., and Landy, H.J. (1994) Drug resistance in brain tumors. J. Neurooncol. 20, 165-176.

Finlay, J.L. (1999) The role of high-dose chemotherapy and stem cell rescue in the treatment of malignant brain tumors: A reappraisal. Pediatr. Transplant. 3 (Suppl. 1), 87-95.

Finlay, J.L., Goldman, S., Wong, M.C., Cairo, M., Garvin, J., August, C., Cohen, B.H., Stanley, P., Zimmerman, R.A., Bostrom, B., Geyer, J.R., Harris, R.E., Sanders, J., Yates, A.J., Boyett, J.M., and Packer, R.J. (1996) Pilot study of high-dose thiotepa and etoposide with autologous bone marrow rescue in children and young adults with recurrent CNS tumors. The Children's Cancer Group. J. Clin. Oncol. 14, 2495-2503.

Friedman, H.S., Petros, W.P., Friedman, A.H., Schaaf, L.J., Kerby, T., Lawyer, J., Parry, M., Houghton, P.J., Lovell, S., Rasheed, K., Cloughsey, T., Stewart, E.S., Colvin, O.M., Provenzale, J.M., McLendon, R.E., Bigner, D.D., Cokgor, I., Haglund, M., Rich, J., Ashley, D., Malczyn, J., Elfring, G.L., and Miller, L.L. (1999) Irinotecan therapy in adults with recurrent or progressive malignant glioma. J. Clin. Oncol. 17, 1516-1525.

Furman, W.L., Stewart, C.F., Poquette, C.A., Pratt, C.B., Santana, V.M., Zamboni, W.C., Bowman, L.C., Ma, M.K., Hoffer, F.A., Meyer, W.H., Pappo, A.S., Walter, A.W., and Houghton, P.J. (1999) Direct translation of a protracted irinotecan schedule from a xenograft model to a phase I trial in children. J. Clin. Oncol. 17, 1815-1824.

Graham, M.L., Herndon, J.E., II, Casey, J.R., Chaffee, S., Ciocci, G.H., Krischer, J.P., Kurtzberg, J., Laughlin, M.J., Longee, D.C., Olson, J.F., Paleologus, N., Pennington, C.N., and Friedman, H.S. (1997) Highdose chemotherapy with autologous stem-cell rescue in patients with recurrent and high-risk pediatric brain tumors. J. Clin. Oncol. 15, 1814-1823.

Hare, C.B., Elion, G.B., Houghton, P.J., Houghton, J.A., Keir, S., Marcelli, S.L., Bigner, D.D., and Friedman, H.S. (1997) Therapeutic efficacy of the topoisomerase I inhibitor 7-ethyl-10-(4-[1-piperidino]-1piperidino)-carbonyloxy-camptothecin against pediatric and adult cen- tral nervous system tumor xenografts. Cancer Chemother. Pharmacol. 39, 187-191.

Henson, J.W., Cordon-Cardo, C., and Posner, J.B. (1992) P-glycoprotein expression in brain tumors. J. Neurooncol. 14, 37-43.

Houghton, P.J., Stewart, C.F., Thompson, J., Santana, V.M., Furman, W.L., and Friedman, H.S. (1998) Extending principles learned in model systems to clinical trials design. Oncology (Huntingt.) 12, 84-93.

Houghton, P.J., Stewart, C.F., Cheshire, P.J., Richmond, L.B., Kirstein, M.N., Poquette, C.A., Tan, M., Friedman, H.S., and Brent, T.P. (2000) Antitumor activity of temozolomide combined with irinotecan is partly independent of $\mathrm{O}^{6}$-methylguanine-DNA methyltransferase and mismatch repair phenotypes in xenograft models. Clin. Cancer Res. 6, 4110-4118.

Kawato, Y., Aonuma, M., Hirota, Y., Kuga, H., and Sato, K. (1991) Intracellular roles of $\mathrm{SN}-38$, a metabolite of the camptothecin derivative CPT-11, in the antitumor effect of CPT-11. Cancer Res. 51, 4187-4191.

Kono, A., and Hara, Y. (1991) Conversion of CPT-11 into SN-38 in human tissues [Japanese]. Gan To Kagaku Ryoho 18, 2175-2178.

Levy, R.H. (1995) Cytochrome P450 isozymes and antiepileptic drug interactions. Epilepsia 36 (Suppl. 5), S8-S13.

Patel, V.J., Elion, G.B., Houghton, P.J., Keir, S., Pegg, A.E., Johnson, S.P., Dolan, M.E., Bigner, D.D., and Friedman, H.S. (2000) Scheduledependent activity of temozolomide plus CPT-11 against a human central nervous system tumor-derived xenograft. Clin. Cancer Res. 6, 4154-4157.

Phillips, P.C. (1991) Antineoplastic drug resistance in brain tumors. Neurol. Clin. 9, 383-404.

Pommier, Y., Tanizawa, A., and Kohn, K.W. (1994) Mechanisms of topoisomerase I inhibition by anticancer drugs. Adv. Pharmacol. 29B, 73-92.

Pourquier, P., Waltman, J.L., Urasaki, Y., Loktionova, N.A., Pegg, A.E., Nitiss, J.L., and Pommier, Y. (2001) Topoisomerase I-mediated cytotoxicity of $\mathrm{N}$-methyl-N'-nitro-N-nitrosoguanidine: Trapping of topoisomerase I by the $\mathrm{O}^{6}$-methylguanine. Cancer Res. 61, 53-58.

Ratain, M.J. (2000) Insights into the pharmacokinetics and pharmacodynamics of irinotecan. Clin. Cancer Res. 6, 3393-3394.

Rothenberg, M.L., Kuhn, J.G., Schaaf, L.J., Drengler, R.L., Eckhardt, S.G., VilIalona-Calero, M.A., Hammond, L., Miller, L.L., Petit, R.G., Rowinsky, E.K., and Von Hoff, D.D. (1998) Alternative dosing schedules for irinotecan. Oncology (Huntingt.) 12 (Suppl. 6), 68-71.

Santos, A., Zanetta, S., Cresteil, T., Deroussent, A., Pein, F., Raymond, E., Vernillet, L., Risse, M.L., Boige, V., Gouyette, A., and Vassal, G. (2000) Metabolism of irinotecan (CPT-11) by CYP3A4 and CYP3A5 in humans. Clin. Cancer. 6, 2012-2020.

Slichenmyer, W.J., Rowinsky, E.K., Grochow, L.B., Kaufmann, S.H., and Donehower, R.C. (1994) Camptothecin analogues: Studies from the Johns Hopkins Oncology Center. Cancer Chemother. Pharmacol. 34, S53-S57.

Vassal, G., Boland, I., Santos, A., Bissery, M.C., Terrier-Lacombe, M.J., Morizet, J., Sainte-Rose, C., Lellouch-Tubiana, A., Kalifa, C., and Gouyette, A. (1997) Potent therapeutic activity of irinotecan (CPT-11) and its schedule dependency in medulloblastomaxenografts in nude mice. Int. J. Cancer73, 156-163.

Vassal, G., Pondarre, C., Boland, I., Cappelli, C., Santos, A., Thomas, C., Lucchi, E., Imadalou, K., Pein, F., Morizet, J., and Gouyette, A. (1998) Preclinical development of camptothecin derivatives and clinical trials in pediatric oncology. Biochimie 80, 271-280.

von Hoff, D. (1996) Future directions for clinical research with CPT-11 (irinotecan). Eur. J. Cancer 32A (Suppl. 3), S9-S12. 